\title{
Tolerability and camouflaging effect of corrective makeup for acne: results of a clinical study of a novel face compact cream
}

This article was published in the following Dove Press journal:

Clinical, Cosmetic and Investigational Dermatology

II October 2016

Number of times this article has been viewed

\section{Giuseppe Monfrecola \\ Sara Cacciapuoti \\ Claudia Capasso \\ Mario Delfino \\ Gabriella Fabbrocini}

Department of Clinical Medicine and Surgery, Section of Dermatology, University of Naples Federico II, Naples, Italy
Correspondence: Giuseppe Monfrecola Department of Clinical Medicine and Surgery, Section of Dermatology, University of Naples Federico II, Via S. Pansini 5, 80I3I Naples, Italy

$\mathrm{Tel}+39817462455$

Fax +39817462442

Email giuseppe.monfrecola@unina.it
Background: A novel face compact cream (FCC) containing a new patented formulation was recently developed to provide acne patients with cosmetic camouflage for their lesions and to have beneficial effects on the multifactorial components of the disease. This pilot investigation aimed to evaluate the real-life tolerability, potential for comedogenicity and covering effect provided by this FCC.

Methods: This single-center study evaluated the FCC applied once daily for 28 days in 20 females with facial acne. Tolerability was assessed by rating skin reactions on a scale from $1=$ absent to 4 =evident. Comedogenicity potential was evaluated by determining the number of facial acne lesions before and after use of the FCC. The covering effect was rated in ten patients 30 minutes after application on a scale from $1=$ none to $5=$ excellent. Patients rated their opinions on the FCC on day 28 using a questionnaire.

Results: Assessment of tolerability on days 0, 14, and 28 showed that skin reactions, including erythema, edema, dryness, desquamation, tight feeling, itching, and burning, were absent in all patients. The FCC was noncomedogenic and provided a significant $15.8 \%$ reduction in facial acne lesions after 28 days $(P<0.001)$. The FCC provided a good covering effect 30 minutes after application in $80 \%$ of patients. All patients $(100 \%)$ were satisfied with the FCC, with 90\% agreeing that the FCC was effective and $80 \%$ stating that the FCC improved their skin.

Conclusion: The FCC was positively perceived, well tolerated, noncomedogenic, and provided an effective covering of acne in this small group of female patients with 1 month of follow-up. Keywords: acne, comedones, dermatocosmetic, tolerability

\section{Introduction}

Acne is a chronic inflammatory disease of the pilosebaceous unit. ${ }^{1,2}$ The disease is most common during adolescence, affecting over $80 \%$ of teenagers, but also affects individuals pre- and postadolescence, with over $40 \%$ of adults in their twenties having acne. ${ }^{3,4}$ The prevalence of acne is greater in teenage boys compared with girls, although adult female acne is more prevalent than adult male acne. ${ }^{4}$ This highly visible disease causes psychological effects, such as depression and anxiety, and can lead to facial scarring in up to $20 \%$ of teenagers. ${ }^{1,5}$ The resulting impact on patients' quality of life is estimated to be similar to that of other major medical conditions, including asthma, epilepsy, diabetes, arthritis, and coronary heart disease. ${ }^{6}$ Acne has a particularly strong impact on teenagers, affecting their self-esteem and social functioning. The self-consciousness and social inhibition that the disease causes can affect school performance as well as participation in sports and social activities. ${ }^{7}$ 
Acne is a multifactorial disease that needs to be treated with an approach that can target as many of the underlying causative factors as possible. The disease results from the interplay of four key factors: increased sebum production, altered keratinization, colonization of the follicle by Propionibacterium acnes, and inflammation. ${ }^{8}$ Current global treatment guidelines recommend fixed combination therapy with a topical retinoid and antimicrobial agent for the majority of acne patients. ${ }^{8}$

There is increasing interest in cosmetic products as components of acne patients' overall management plans, which can complement the medical regimen. ${ }^{9}{ }^{10}$ In females, in particular, there is a need for cosmetic products that can effectively cover the signs of this highly visible skin condition to reduce the emotional impact of the disease. Use of cosmetics can also increase acne patients' adherence with their medical regimen, which is estimated to be poor in 50\% of patients. ${ }^{11}$ However, clinical studies of the efficacy and safety of existing dermatocosmetic treatments for acne are lacking, and some products need to be avoided as they may worsen, rather than improve, the disease. ${ }^{10}$

A novel face compact cream (FCC) was recently developed for skin affected by and prone to acne to provide patients with daily cosmetic camouflage specific for their lesions and also to have beneficial effects on the multifactorial components that cause acne. The components of the FCC and their effects on the underlying causes of acne are summarized in Table 1. The FCC contains selective photofilters to provide protection against ultraviolet B (UVB) rays, while allowing partial penetration of UVA rays. The rationale for this selective photofiltration is that specific wavelengths of UVA, around $400 \mathrm{~nm}$, may have beneficial effects on acne-prone and acne-affected skin by providing anti-inflammatory effects, ${ }^{12-14}$ whereas UVB has many negative effects, including the induction of inflammation, ${ }^{15-18}$ increased proliferation of keratinocytes, ${ }^{19}$ and increased sebum production. ${ }^{20,21}$ The other active components of the FCC target

Table I Components and key activities of face compact cream

\begin{tabular}{|c|c|}
\hline Component & Action \\
\hline Selective photofilters & $\begin{array}{l}\text { UVB protection while allowing partial } \\
\text { penetration of UVA }\end{array}$ \\
\hline Salix alba (willow bark & Anti-inflammatory effects ${ }^{24-26}$ and reduces \\
\hline extract) & Propionibacterium acnes ${ }^{22}$ \\
\hline I,2-Decanediol & $\begin{array}{l}\text { Reduces } P \text {. acnes and sebum } \\
\text { production }^{22,23,39}\end{array}$ \\
\hline Vitamin $B_{3}$ & $\begin{array}{l}\text { Anti-inflammatory effects and improvement } \\
\text { of the epidermal barrier } 27,29\end{array}$ \\
\hline Soy isoflavones & $\begin{array}{l}\text { Anti-inflammatory and antioxidant effects } \\
\text { and protects DNA from UV damage }{ }^{28,40-42}\end{array}$ \\
\hline Vitamins $C$ and $E$ & Antioxidant effects \\
\hline
\end{tabular}

Abbreviations: DNA, deoxyribonucleic acid; UVA, ultraviolet $A$; UVB, ultraviolet $B$. the principal pathogenic factors of acne. For example, the patented combination of 1,2-decanediol and Salix alba (willow bark extract) synergistically reduce $P$. acnes levels, ${ }^{22}$ and 1,2-decanediol itself also reduces sebum production. ${ }^{23} \mathrm{~S}$. alba, vitamin $\mathrm{B}_{3}$ and soy isoflavones provide anti-inflammatory effects. ${ }^{24-28} \mathrm{In}$ addition, the vitamin $\mathrm{B}_{3}$ component improves the epidermal barrier, and vitamins $\mathrm{C}$ and $\mathrm{E}$ provide antioxidant effects. ${ }^{29}$

The objective of this pilot investigation into the FCC was to evaluate its real-life tolerability, potential for comedogenicity, and covering effect in a small group of female patients with facial acne.

\section{Methods}

\section{Patients}

Participants were recruited by dermatologists working at Farcoderm Srl (San Martino Siccomario, Italy) from their database of volunteers. Female patients with facial acne (10-25 open or closed comedones) aged $\geq 18$ years were eligible for participation in this study. The patients were not receiving pharmacological treatment for their acne and had to agree not to use any acne treatment for $\geq 30$ days before or during the study period. Patients were excluded if they were pregnant or if they were allergic to cosmetic products, toiletries, sunscreens, and/or topical drugs. Patients were also not eligible if they had any other skin disorders on the test area, or if they had a medical history of atopy, which could interfere with the study procedures. All patients provided written informed consent before participating in the study.

\section{Study design}

This open-label study was conducted at the clinical trial research facilities of Farcoderm Srl under the supervision of the University of Naples in accordance with the latest version of the Declaration of Helsinki. This study was approved by the Scientific Ethical Board of the Department of Clinical Medicine and Surgery of University of Naples Federico II - Faculty of Medicine composed by Prof. Mario Delfino (dermatologist; University of Naples), Prof. Massimiliano Scalvenzi (dermatologist; University of Naples), and Drssa Gabriella Calabro (pharmacist; University of Naples). Participation in the study was voluntary and all patients were provided with information on the aims of the study and the potential risks involved.

The FCC (Acnacalm ${ }^{\circledR} /$ Acnapur $^{\circledR}$ moisturizing cream, MEDA, Stockholm, Sweden) was applied once daily in the morning for 28 days. During the first visit, the investigator showed the patient how to apply the FCC. Patients were advised to apply the product as a normal foundation makeup using sufficient quantity to cover all their facial lesions with the help of a sponge and mirror that were included in the packaging to facilitate application. During the week before the start of 
the study and during the study period, patients were asked to wash their face with an affinity gel detergent provided by the investigator. Patients were evaluated by the investigator after 14 and 28 days of using the FCC. The FCC conforms with European Union Regulation (CE) 1223/2009 on cosmetics.

\section{Evaluations}

Skin tolerability was assessed on days 0,14 , and 28 by the investigator. Erythema, edema, dryness, desquamation, tight feeling, itching, and burning were evaluated using the following scale: 1 =absent; 2 =slight reaction; 3 =moderate reaction; and $4=$ evident reaction.

The comedogenic potential of the FCC was assessed by the investigator determining the number of comedones and inflammatory lesions on the face on days 0,14 , and 28 . The cream was to be judged as noncomedogenic if the increase in the percentage of lesions was $<50 \%{ }^{30}$

On day 0 , the covering effect of the FCC was evaluated in ten patients. Each of these patients applied $2 \mathrm{mg} / \mathrm{cm}^{2}$ of cream to a clean face under the supervision of the investigator who then took digital photographs of the treated area before and 30 minutes after application. Three trained assessors evaluated the covering effectiveness of the cream using the following scale: 1 =no covering; 2 =poor covering (natural skin color and imperfections are not sufficiently covered); 3 =fair covering (natural skin color and imperfections are partially visible); 4 =good covering (natural skin color and the majority of imperfections are not visible); and $5=$ excellent covering (natural skin color and imperfections are not visible).

On day 28, patients completed a questionnaire that evaluated their satisfaction and opinions on the FCC. The following questions were asked: 1) Is the FCC effective? 2) Did the FCC improve your skin? 3) Did the FCC help you to be happier by giving you a more even complexion? 4) Is the FCC pleasant? 5) Are you satisfied with the FCC? and 6) Would you continue to use the FCC?

They also rated their facial skin using a visual analog scale (VAS) with scores ranging from 0 (no signs of acne) to 10 (serious acne). The VAS was chosen as it is an easy and intuitive way for patients to assess the severity of their acne.

All evaluations were carried out after the skin had been cleaned and before application of the FCC, with the exception of the day 0 evaluation of the covering effect, which was done 30 minutes after application of the cream.

\section{Statistical analyses}

A sample of 20 patients was considered sufficient to provide initial information on the real-life tolerability and comedogenicity of the FCC; no formal sample size calculation was conducted. Ten patients were included in the evaluation of the covering effect as patients had to provide consent for their photographs to be taken and distributed. The patients also gave consent for their photos to be included in this study. Given that this parameter depended on the characteristics of the formulation to color the skin and could be objectively evaluated, a sample of ten patients was deemed appropriate.

Data were reported using descriptive statistics. The effect of the FCC on the number of facial acne lesions was statistically analyzed using the Wilcoxon signed-rank test.

\section{Results}

This study enrolled 20 Caucasian adult female acne patients; their mean age was 33.4 years (range $21-46$ years).

\section{Tolerability}

Assessment of tolerability on days 0,14 , and 28 indicated that the FCC was well tolerated. Skin reactions, including erythema, edema, dryness, desquamation, tight feeling, itching, and burning, were absent in all patients at all evaluated time points, with no increase in frequency following application of the FCC versus baseline.

\section{Comedogenicity}

As shown in Figure 1, 28 days of use of the FCC did not lead to an increase in facial acne lesions, demonstrating that the product is noncomedogenic. Instead, there was a significant $8.2 \%$ reduction in comedones and inflammatory lesions after 14 days (mean: 15.8 to 14.5 lesions; $P=0.027$ ) and a significant $15.8 \%$ reduction after 28 days (mean: 15.8 to 13.3 lesions; $P<0.001$ ).

\section{Covering effect}

The FCC provided a good covering effect 30 minutes after application in $80 \%$ of patients and an excellent covering effect in $10 \%$ of patients as evaluated by three trained assessors (Figure 2A). An example of the covering effect provided by the FCC is shown in Figure 2B.

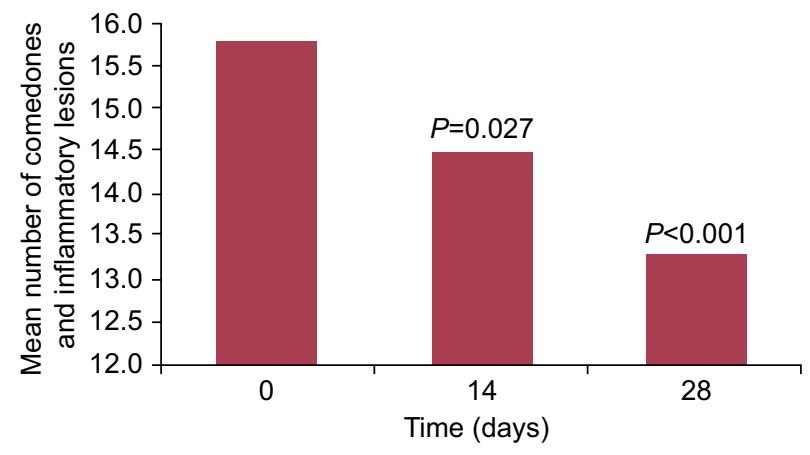

Figure I Reduction in facial acne lesions $(\mathrm{N}=20)$. 

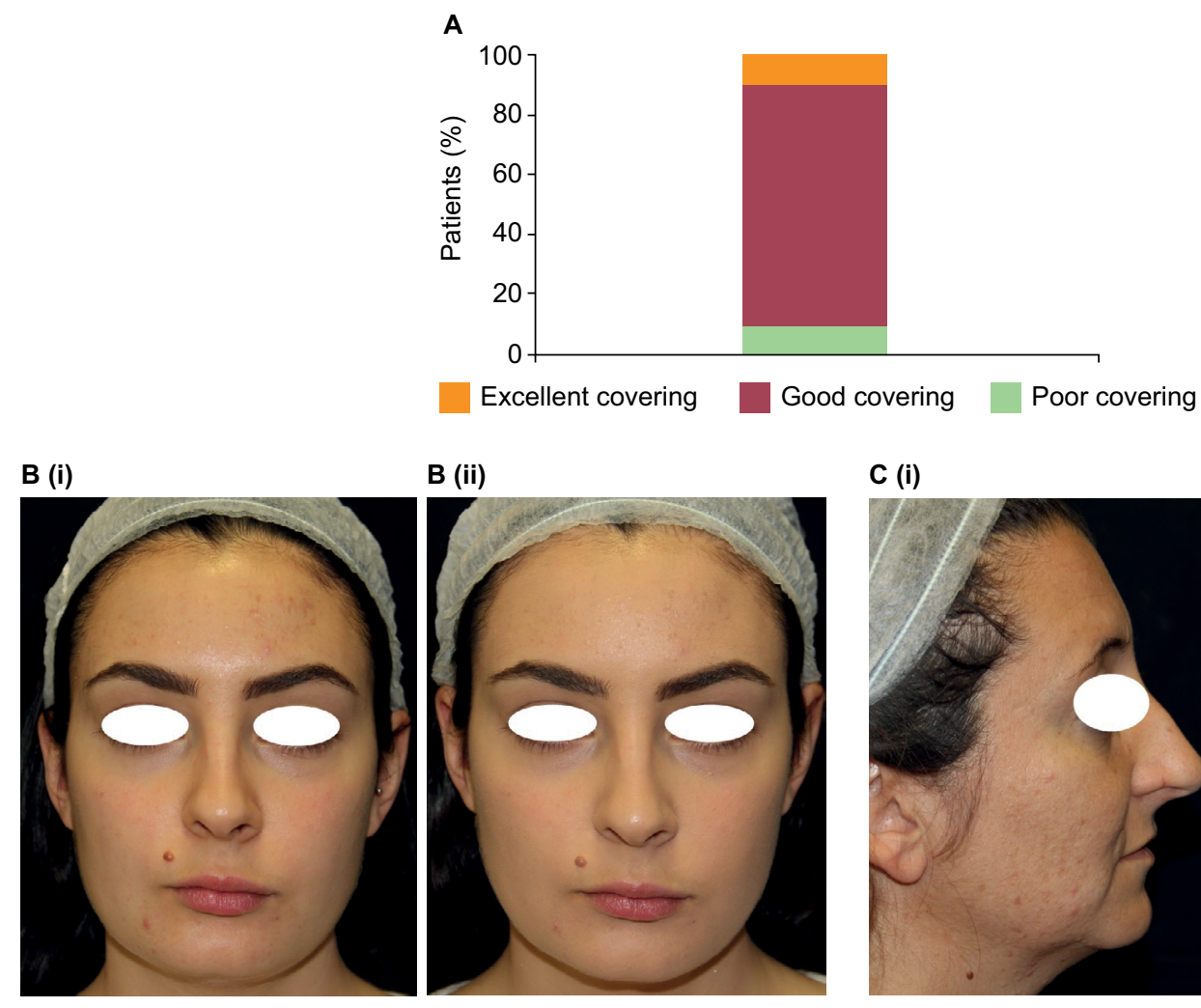

C (i)

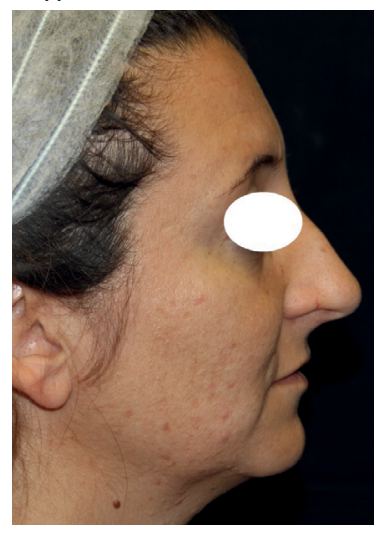

C (ii)

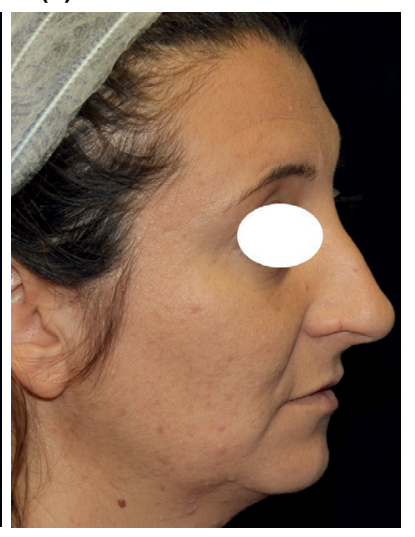

Figure 2 Covering effect. (A) Evaluation of covering effect 30 minutes after application $(\mathrm{N}=10)$. (B and C) Example patients from the study showing the covering effect before (i) and 30 minutes after application (ii).

\section{Patient satisfaction}

The patients in this study observed that the FCC led to an improvement in their acne. Before application, the mean VAS score for the patients' rating of their facial skin was 4.7. After 28 days of use, there was a $64 \%$ improvement in the mean VAS score for the patients' rating of their facial skin, which was reduced to 1.7 (Figure 3A).

The patients also provided a positive opinion on the FCC (Figure 3B): $90 \%$ agreed that the cream was effective; $80 \%$ agreed that the cream improved their skin; $95 \%$ agreed that the cream helped them to be happier by providing a more even complexion; and $100 \%$ agreed that the cream is pleasant. Furthermore, $100 \%$ of patients reported that they were satisfied with the FCC and 95\% stated that they would continue to use the cream.

\section{Discussion}

The results of this study indicate that the FCC can provide many potential benefits to acne patients. The effective cosmetic camouflaging effect of the cream provides an immediate improvement in the skin's appearance by covering the imperfections, which are typical of acne. Of particular importance in this regard was the demonstration that the
FCC was well tolerated and that it was not comedogenic, which is a prerequisite for use on skin affected by or prone to acne. This is due to the specific formulation of the FCC (an oil-free vehicle without alcohol or perfume), which is designed to respect acne-prone and acne-affected skin. The components of the FCC also provide selective UV filtration and additionally target several of the underlying causes of acne (eg, the patented combination of $S$. alba and 1,2-decanediol reduce $P$. acnes, ${ }^{22}$ and $S$. alba and Vitamin $\mathrm{B}_{3}$ reduce inflammation ${ }^{24-27}$ ) and so the cream was associated with a significant reduction in acne lesions after once-daily application for 28 days. Finally, the results of this study highlight the potential of this daily makeup product to complement the action of a pharmacological acne treatment to ensure optimal and rapid reduction of the signs and symptoms of this skin condition and avoid possible flares of acne.

The current study represents a pilot investigation of the real-life tolerability, potential for comedogenicity and covering effect of the FCC in a small group of female acne patients. The design of the study was chosen based on the endpoints that were being evaluated, and since the FCC is a dermatocosmetic product that is anticipated to have an adjuvant role in acne management, rather than treating acne per se. The 
A

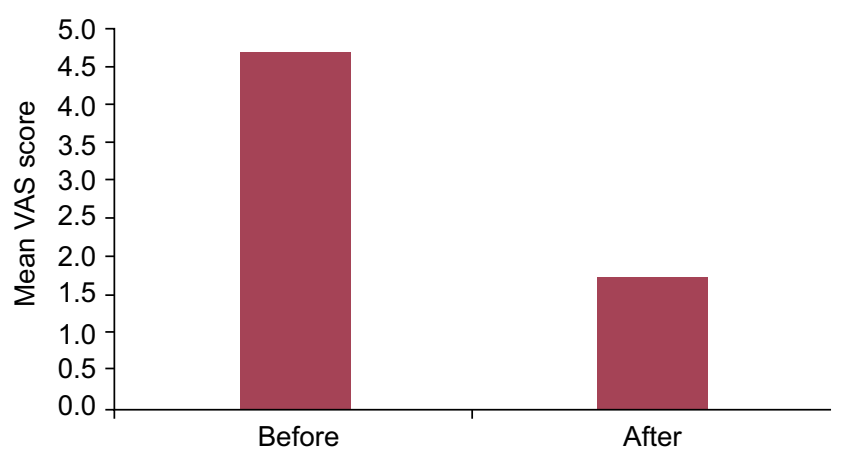

B

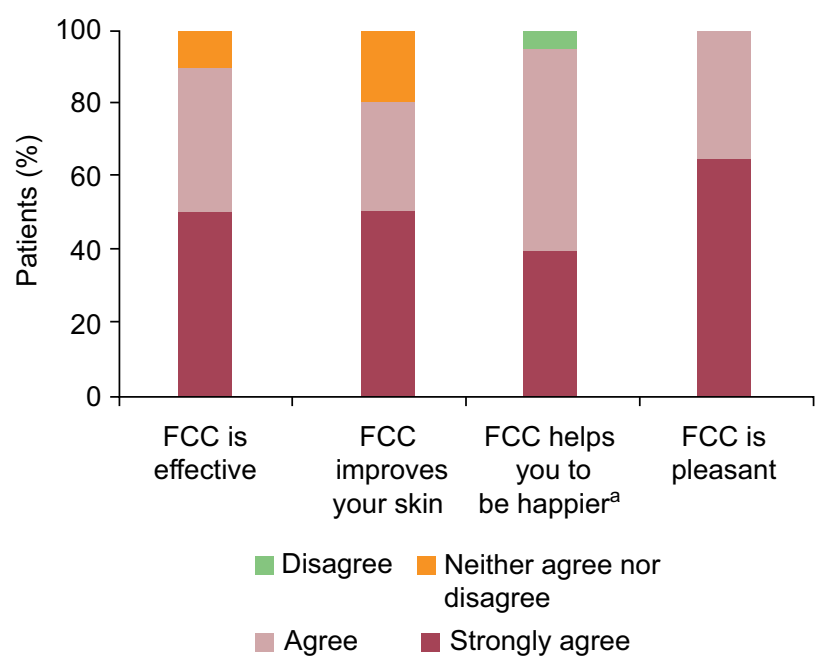

Figure 3 Patient evaluations.

(A) Patient rating of acne before and after FCC. (B) Patient satisfaction with the FCC after 28 days of use.

Notes: (A) "How do you judge your face skin before/after using FCC?" Scale ( $0=$ no signs of acne; $10=$ serious acne). (B) a ${ }^{2}$ Gives you a more even complexion. Abbreviations: FCC, face compact cream; VAS, visual analog scale.

efficacy of the FCC in reducing comedones observed in this study is not conclusive, but hypothesis generating, and should be further investigated in an appropriately controlled clinical study. The natural camouflaging effect provided by the FCC together with its beneficial effects against acne may together translate into a positive impact on patients' quality of life, which is severely affected by this highly visible skin condition. ${ }^{6}$ In addition, the majority of patients in this study had a positive opinion of the FCC, with $95 \%$ of them reporting that the cream helped them to be happier, also suggesting that it may have a positive influence on patients' quality of life.

The beneficial effect of cosmetic camouflage on the quality of life of patients with acne and other disfiguring dermatological diseases has been demonstrated in several other studies. A study in 18 female acne patients showed a significant improvement in the Skindex-16 score (from 30.6 to $14.6, P<0.01$ ) and a significant reduction in anxiety assessed with the State-Trait Anxiety Inventory (from 45.6 to $37.4, P<0.05$ ) evaluated up to 4 weeks after patients were trained by a makeup artist to apply cosmetics suitable for acne-affected skin, while their acne was also treated. ${ }^{31}$ Another study showed that a medical corrective makeup lesson in which patients received training on how to cover up apparent lesions led to a significant improvement in quality of life as measured using the Dermatology Life Quality Index (DLQI) in 25 acne patients (as well as in patients with other dermatological diseases) 1 month after the lesson $(P=0.006) .{ }^{32}$ These results were confirmed in a study that also showed a significant improvement in the mean DLQI score in 129 patients with facial dermatological conditions, including acne, 1 month after a corrective makeup lesson (from 9.9 to $3.5 ; P<0.0001$ ), with $99 \%$ of patients reporting a noticeable improvement in their face after makeup application. ${ }^{33}$ A significant improvement in DLQI was also reported in a study of 20 female patients, including eight with acne and nine with rosacea, after once-daily application of decorative cosmetics for 2 weeks ( 9.2 to $5.5 ; P=0.0009) .{ }^{34}$ Two further investigations into the effects of cosmetic camouflage in pediatric patients with a variety of visible skin anomalies also showed that the intervention was associated with a significant and sustained improvement in quality of life. ${ }^{35,36}$ The mean Children's DLQI decreased significantly from 5.1 at baseline to 2.1 at 6 months in the larger of these studies, which included 41 patients $(P<0.001){ }^{35}$

Some dermatologists may discourage acne patients from using makeup since they consider it may aggravate their condition. ${ }^{33}$ Similarly, many acne patients consider that makeup may worsen the disease. ${ }^{37}$ The results of this study challenge these opinions by showing the beneficial effects of this particular FCC, which contains specific ingredients that are beneficial in treating acne, in contrast to other commonly used dermatocosmetics for acne. The results highlight the need for dermatologists and patients to select appropriate welltolerated, noncomedogenic, nonallergenic makeup products containing active ingredients against acne, which have a beneficial rather than detrimental effect against this common skin disease. ${ }^{38}$ However, it should also be recognized that not every patient with visible acne will choose to camouflage their condition, and those who start to cover their acne lesions may feel pressure to always have to cover them up. 
Limitations of the current study include its design without a control group, the small number of patients evaluated and the relatively short duration of follow-up. Future studies should evaluate this FCC over longer durations in larger population of patients and in combination with other pharmacological acne therapies versus appropriate controls. Additional studies could also evaluate the optimal duration of treatment, whether treatment is beneficial after lesion clearance, and any postuse effect of the FCC by including a wash-out dermatological assessment of study participants. This particular FCC was developed as makeup for use in females. As men are generally not comfortable with applying makeup, an alternative formulation may need to be developed and evaluated for use in covering acne in males.

In conclusion, the FCC evaluated in this study was well tolerated, noncomedogenic, and provided an effective covering of acne in this small group of female patients with 1 month of follow-up. The cream was positively perceived by patients in terms of improving their skin and mood, which may result in an improvement in their quality of life. The results of this study support the use of this FCC as daily makeup to cover skin imperfections with the additional potential benefit of reducing the signs and symptoms of acne. The results also support the use of other dermatocosmetic products that contain the same active ingredients as part of the daily skin care regimen for patients affected by acne.

\section{Acknowledgments}

This study was funded by MEDA. Medical writing assistance in the preparation of this manuscript was provided by David Harrison, Medscript Ltd, funded by MEDA.

\section{Disclosure}

The authors report no conflicts of interest in this work.

\section{References}

1. Williams HC, Dellavalle RP, Garner S. Acne vulgaris. Lancet. 2012; 379(9813):361-372.

2. Gollnick HP, Finlay AY, Shear N. Can we define acne as a chronic disease? If so, how and when? Am J Clin Dermatol. 2008;9(5): 279-284.

3. Karciauskiene J, Valiukeviciene S, Gollnick H, Stang A. The prevalence and risk factors of adolescent acne among schoolchildren in Lithuania: a cross-sectional study. J Eur Acad Dermatol Venereol. 2014;28(6):733-740.

4. Collier CN, Harper JC, Cafardi JA, Cantrell WC, Wang W, Foster KW, Elewski BE. The prevalence of acne in adults 20 years and older. $J \mathrm{Am}$ Acad Dermatol. 2008;58(1):56-59.

5. Fried RG, Webster GF, Eichenfield LF, Friedlander SF, Fowler JF, Jr., Levy ML. Medical and psychosocial impact of acne. Semin Cutan Med Surg. 2010;29(2 Suppl 1):9-12.
6. Cresce ND, Davis SA, Huang WW, Feldman SR. The quality of life impact of acne and rosacea compared to other major medical conditions. J Drugs Dermatol. 2014;13(6):692-697.

7. Krakowski AC, Stendardo S, Eichenfield LF. Practical considerations in acne treatment and the clinical impact of topical combination therapy. Pediatr Dermatol. 2008;25(Suppl 1):1-14.

8. Thiboutot D, Gollnick H, Bettoli V, et al. New insights into the management of acne: an update from the Global Alliance to Improve Outcomes in Acne group. J Am Acad Dermatol. 2009;60(5 Suppl):S1-S50.

9. Del Rosso JQ. The role of skin care as an integral component in the management of acne vulgaris: part 1: the importance of cleanser and moisturizer ingredients, design, and product selection. $J$ Clin Aesthet Dermatol. 2013;6(12):19-27.

10. Araviiskaia E, Dreno B. The role of topical dermocosmetics in acne vulgaris. J Eur Acad Dermatol Venereol. 2016;30(6):926-935.

11. Dreno B, Thiboutot D, Gollnick H, et al. Large-scale worldwide observational study of adherence with acne therapy. Int J Dermatol. 2010;49(4):448-456.

12. Shnitkind E, Yaping E, Geen S, Shalita AR, Lee WL. Anti-inflammatory properties of narrow-band blue light. $J$ Drugs Dermatol. 2006;5(7):605-610.

13. Kwon HH, Lee JB, Yoon JY, et al. The clinical and histological effect of home-use, combination blue-red LED phototherapy for mild-tomoderate acne vulgaris in Korean patients: a double-blind, randomized controlled trial. Br J Dermatol. 2013;168(5):1088-1094.

14. Monfrecola G, Lembo S, Cantelli M, Ciaglia E, Scarpato L, Fabbrocini $\mathrm{G}$, Balato A. The effect of visible blue light on the differentiation of dendritic cells in vitro. Biochimie. 2014;101:252-255.

15. Clydesdale GJ, Dandie GW, Muller HK. Ultraviolet light induced injury: immunological and inflammatory effects. Immunol Cell Biol. 2001;79(6):547-568.

16. Kondo S, Kono T, Sauder DN, McKenzie RC. IL-8 gene expression and production in human keratinocytes and their modulation by UVB. J Invest Dermatol. 1993;101(5):690-694.

17. Lee WJ, Park KH, Sohn MY, Lee WC, Lee SJ, Kim do W. Ultraviolet $\mathrm{B}$ irradiation increases the expression of inflammatory cytokines in cultured sebocytes. J Dermatol. 2013;40(12):993-997.

18. Oxholm A, Oxholm P, Staberg B, Bendtzen K. Immunohistological detection of interleukin I-like molecules and tumour necrosis factor in human epidermis before and after UVB-irradiation in vivo. $\mathrm{Br} J$ Dermatol. 1988;118(3):369-376.

19. Del Bino S, Vioux C, Rossio-Pasquier P, Jomard A, Demarchez M, Asselineau D, Bernerd F. Ultraviolet B induces hyperproliferation and modification of epidermal differentiation in normal human skin grafted on to nude mice. Br J Dermatol 2004;150(4):658-667.

20. Akitomo Y, Akamatsu H, Okano Y, Masaki H, Horio T. Effects of UV irradiation on the sebaceous gland and sebum secretion in hamsters. J Dermatol Sci. 2003;31(2):151-159.

21. Lesnik RH, Kligman LH, Kligman AM. Agents that cause enlargement of sebaceous glands in hairless mice. II. Ultraviolet radiation. Arch Dermatol Res. 1992;284(2):106-108.

22. Monfrecola G, Zanardi A, Mantegazza R, Gasparri F. Anti-bacterial activity of Salix alba (willow bark extract) and 1,2-decanediol against Propionibacterium acnes. Poster presented at: EADV; 2015;P0007.

23. Angelova-Fischer I, Rippke F, Fischer TW, Neufang G, Zillikens D. A double-blind, randomized, vehicle-controlled efficacy assessment study of a skin care formulation for improvement of mild to moderately severe acne. J Eur Acad Dermatol Venereol. 2013;27(Suppl 2):6-11.

24. Bonaterra GA, Heinrich EU, Kelber O, Weiser D, Metz J, Kinscherf R. Anti-inflammatory effects of the willow bark extract STW 33-I (Proaktiv((R))) in LPS-activated human monocytes and differentiated macrophages. Phytomedicine. 2010;17(14):1106-1113.

25. Fiebich BL, Chrubasik S. Effects of an ethanolic salix extract on the release of selected inflammatory mediators in vitro. Phytomedicine. 2004;11(2-3):135-138.

26. Khayyal MT, El-Ghazaly MA, Abdallah DM, Okpanyi SN, Kelber O, Weiser D. Mechanisms involved in the anti-inflammatory effect of a standardized willow bark extract. Arzneimittelforschung. 2005;55(11):677-687. 
27. Monfrecola G, Gaudiello F, Cirillo T, Fabbrocini G, Balato A, Lembo S. Nicotinamide downregulates gene expression of interleukin-6, interleukin-10, monocyte chemoattractant protein-1, and tumour necrosis factor-alpha gene expression in $\mathrm{HaCaT}$ keratinocytes after ultraviolet B irradiation. Clin Exp Dermatol. 2013;38(2):185-188.

28. Berson DS. Natural antioxidants. J Drugs Dermatol. 2008;7(7 Suppl): s7-s12.

29. Tanno O, Ota Y, Kitamura N, Katsube T, Inoue S. Nicotinamide increases biosynthesis of ceramides as well as other stratum corneum lipids to improve the epidermal permeability barrier. Br J Dermatol. 2000; 143(3):524-531.

30. Mills OH, Jr., Kligman AM. A human model for assessing comedogenic substances. Arch Dermatol. 1982;118(11):903-905.

31. Hayashi N, Imori M, Yanagisawa M, Seto Y, Nagata O, Kawashima M. Make-up improves the quality of life of acne patients without aggravating acne eruptions during treatments. Eur J Dermatol. 2005;15(4): 284-287.

32. Peuvrel L, Quereux G, Brocard A, et al. Evaluation of quality of life after a medical corrective make-up lesson in patients with various dermatoses. Dermatology. 2012;224(4):374-380.

33. Seite S, Deshayes P, Dreno B, et al. Interest of corrective makeup in the management of patients in dermatology. Clin Cosmet Investig Dermatol. 2012;5:123-128.

34. Boehncke WH, Ochsendorf F, Paeslack I, Kaufmann R, Zollner TM. Decorative cosmetics improve the quality of life in patients with disfiguring skin diseases. Eur J Dermatol. 2002;12(6):577-580.
35. Ramien ML, Ondrejchak S, Gendron R, Hatami A, McCuaig CC, Powell J, Marcoux D. Quality of life in pediatric patients before and after cosmetic camouflage of visible skin conditions. J Am Acad Dermatol. 2014;71(5):935-940.

36. Padilla-Espana L, del Boz J, Ramirez-Lopez MB, Fernandez-Sanchez ME. Camouflage therapy workshop for pediatric dermatology patients: a review of 6 cases. Actas Dermosifiliogr. 2014;105(5):510-514.

37. Poli F, Auffret N, Beylot C, et al. Acne as seen by adolescents: results of questionnaire study in 852 French individuals. Acta Derm Venereol. 2011; 91(5):531-536.

38. Draelos ZD. Cosmetics in acne and rosacea. Semin Cutan Med Surg 2001;20(3):209-214.

39. Schmaus G, Lange S, Pfeiffer A, Joppe H, Pillai R. 1,2-Decanediol - A new cosmetic for multiple applications. Poster presented at: 25 th International Federation of Societies of Cosmetic Chemists Congress; 2008.

40. Iovine B, Garofalo M, Orefice M, Giannini V, Gasparri F, Monfrecola G, Bevilacqua MA. Isoflavones in aglycone solution enhance ultraviolet B-induced DNA damage repair efficiency. Clin Exp Dermatol. 2014;39(3):391-394.

41. Iovine B, Iannella ML, Gasparri F, Giannini V, Monfrecola G, Bevilacqua MA. A comparative analysis of the photo-protective effects of soy isoflavones in their aglycone and glucoside forms. Int $\mathrm{J} \mathrm{Mol} \mathrm{Sci}$. 2012;13(12):16444-16456.

42. Iovine B, Iannella ML, Gasparri F, Monfrecola G, Bevilacqua MA. Synergic effect of genistein and daidzein on UVB-induced DNA damage: an effective photoprotective combination. J Biomed Biotechnol. 2011 2011:692846.
Clinical, Cosmetic and Investigational Dermatology

\section{Publish your work in this journal}

Clinical, Cosmetic and Investigational Dermatology is an international, peer-reviewed, open access, online journal that focuses on the latest clinical and experimental research in all aspects of skin disease and cosmetic interventions. This journal is included on PubMed. The manuscript management system is completely online

\section{Dovepress}

and includes a very quick and fair peer-review system, which is all easy to use. Visit http://www.dovepress.com/testimonials.php to read real quotes from published authors 